\title{
Produção de mudas de meloeiro em substrato à base de ramas de mandioca
}

\author{
Murilo Fuentes Pelloso', Bruno Gustavo Aguiar Cardoso Farias², Auricléia Sarmento de Paiva ${ }^{3}$
}

'Universidade Estadual de Maringá - UEM; ${ }^{2}$ Universidade Estadual de Mato Grosso do Sul - UEMS; Universidade Católica Dom Bosco - UCDB. E-mail: murilof.pelloso@hotmail.com

\section{Resumo}

Avaliou-se a produção de mudas de meloeiro acondicionadas em substratos à base de ramas de mandioca trituradas e submetidas a períodos de compostagem. $O$ experimento foi conduzido em ambiente protegido e adotou-se o delineamento inteiramente casualizado, em esquema fatorial $5 \times 2$, cujos tratamentos corresponderam a combinação de cinco períodos de compostagem de ramas de mandioca trituradas ( 0 ; 30; 60; 90 e 120 dias) e duas cultivares de melão (Gaúcho Casca de Carvalho e Melão Amarelo). Na emergência das plântulas, iniciaram-se as avaliações do índice de velocidade de emergência e porcentagem de germinação. Aos 30 dias após a semeadura foram avaliadas altura de plantas, diâmetro de caule, razão altura/diâmetro, comprimento de raízes, massa seca da parte aérea, massa seca das raízes, massa seca total e Índice de qualidade de Dickson. Os dados foram submetidos à análise de variância e, ao ser constatado significância pelo teste $\mathrm{F}$, as médias das cultivares foram comparadas pelo teste de Tukey ao nível de significância de $5 \%$. Para os tempos de compostagem foi realizada regressão. As mudas de meloeiro cv. Melão Amarelo apresentaram melhor desenvolvimento que as da cv. Gaúcho Casca de Carvalho. O período de compostagem de 120 dias é o mais indicado para a produção de substrato para mudas de meloeiro.

Palavras-chave: Composto orgânico; Cucumis melo L.; Propagação.

\section{Production of melon seedlings in substrate based on cassava branch}

\begin{abstract}
Evaluated the production of melon seedlings placed on substrates based on shredded cassava branches and submitted to composting periods. The experiment was carried out in a protected environment and a completely randomized design in a $5 \times 2$ factorial scheme was adopted. The treatments corresponded to the combination of five composting periods of shredded cassava branches (0,30,60, 90 and 120 days) and two melon cultivars (Gaúcho Casca de Carvalho and Melão Amarelo). At seedling emergence, the emergence speed index and emergence percentage evaluations were started. At 30 days after sowing, plant height, stem diameter, height/diameter ratio, root length, shoot dry mass, root dry mass, total dry mass and Dickson Quality Index were evaluated. Data were subjected to analysis of variance and when significance was found by the $\mathrm{F}$ test, the cultivars averages were compared by Tukey test at a significance level of $5 \%$. For the composting times regression was performed. Melon seedlings cv. Melão Amarelo presents better development than melon cv. Gaúcho Casca de Carvalho. The composting period of 120 days is the most suitable for the production of substrate for melon seedlings.
\end{abstract}

Keywords: Organic compost; Cucumis melo L.; Propagation.

\section{Introdução}

O melão (Cucumis melo L.), hortaliça fruto, pertencente à família Curcubitaceae, apresenta ampla aceitação no Brasil e no mundo (YASIR et al., 2016). Nacionalmente, a cultura é produzida, sobretudo na região Nordeste, que produz anualmente cerca de 514 mil toneladas do fruto, compreendendo aproximadamente $95 \%$ da produção brasileira (IBGE, 2017). 
Dentre os fatores que influenciam diretamente no desempenho agronômico de hortaliças, destaca-se a produção adequada de mudas (ZEIST et al., 2017). Estas devem apresentar uniformidade, sanidade e bom desenvolvimento de parte aérea e sistema radicular, a fim de manter desenvolvimento satisfatório quando transplantadas, e capacidade de resistir a possíveis condições adversas no campo (CALDEIRA et al., 2008; CORREIA et al., 2013). Além disso, ressalta-se a importância da qualidade das sementes, material genético utilizado, ambiente de produção, recipientes e substratos.

De maneira geral, os substratos têm por função substituir parcial ou totalmente o uso do solo no cultivo de mudas, podendo estes ser compostos por materiais de origem mineral, artificial, animal ou vegetal, ou combinações entre estes (ZIETEMANN; ROBERTO, 2007). Os substratos, que influenciam tanto na germinação quanto no desenvolvimento das mudas, são caracterizados por índices técnicos tais como aeração, capacidade de retenção de líquidos, aspectos nutricionais e valor de acidez (CALDEIRA et al., 2008; DUTRA et al., 2012; MEDEIROS et al., 2018).

Para autores como Pires et al. (2008) a utilização de insumos orgânicos na substituição de substratos minerais apresenta amplo potencial. Por sua vez, Kiehl (2012) destaca que os mesmos devem estar devidamente decompostos e beneficiados. Os substratos orgânicos destacam-se ainda pelo baixo custo e facilidade de obtenção, sobretudo quando presentes na própria propriedade rural ou locais próximos, como resíduos de outras culturas e subprodutos de indústria.

Diversos subprodutos agrícolas já foram avaliados como substratos para hortaliças, tais como fibras de cascas de coco (GUISOLFI et al., 2018; SANTOS et al., 2018); cascas de arroz e resíduos de soja (MEDEIROS, et al., 2018); bagaço de cana-de-açúcar (BIASI et al., 1995, ARAGÃO et al., 2011) e ramas de mandioca (LUQUI et al., 2015; COSTA et al., 2015). Entretanto, para a utilização de resíduos orgânicos como substrato, faz-se necessária a realização da compostagem dos mesmos, visando estabilidade dos compostos orgânicos, redução da acidez e salinidade e aumento da disponibilidade de nutrientes para as mudas (GOMES et al., 2008).
Além da região Nordeste, outras regiões brasileiras tem potencial para expansão produtiva da cultura do melão, como a região do Ecótono Cerrado-Pantanal do Mato Grosso do Sul, que apresenta invernos relativamente quentes, baixa umidade relativa do ar e solos de textura média a arenosa, condições consideradas favoráveis à produção desta hortaliça (FILGUEIRA, 2013; BARDIVIESSO et al., 2015). Entretanto, são escassas as informações técnicas para o cultivo do meloeiro na região.

Diante disso, objetivou-se avaliar a germinação e o desenvolvimento de mudas de melão das cultivares Gaúcho Casca de Carvalho e Melão Amarelo acondicionadas em substratos orgânicos à base de ramas de mandioca trituradas e submetidas a períodos de compostagem na região do Ecótono CerradoPantanal.

\section{Material e Métodos}

O experimento foi conduzido na área experimental da Universidade Estadual de Mato Grosso do Sul (UEMS), Unidade Universitária de Aquidauana, localizada nas coordenadas geográficas $20^{\circ} 27^{\prime}$ Sul e $55^{\circ} 40^{\prime}$ Oeste, com altitude aproximada de 174 metros. A região, situada no Ecótono Cerrado-Pantanal, apresenta clima tropical úmido (Aw), conforme KöppenGeiger, temperatura média anual de $29{ }^{\circ} \mathrm{C}$, precipitação média anual em torno de $1.200 \mathrm{~mm}$ com predomínio de chuvas no período de verão e estação seca no inverno (PACHECO et al., 2012).

0 delineamento experimental foi inteiramente casualizado, em esquema fatorial 5 $x$ 2, cujos tratamentos compuseram-se da combinação de cinco períodos de compostagem de ramas de mandioca trituradas $(0 ; 30 ; 60 ; 90$ e 120 dias), como substratos, e duas cultivares de melão (Gaúcho Casca de Carvalho e Melão Amarelo, ambas com garantia de germinação de 96\%), com oito repetições, sendo cada repetição composta por 32 plantas.

Para produção das mudas, foram utilizadas bandejas de poliestireno expandido, de 128 células, com volume de $22,5 \mathrm{~mL}$ por célula. A condução do experimento decorreu em ambiente protegido do tipo viveiro telado, com dimensões de $18,00 \mathrm{~m}$ de comprimento, $6,40 \mathrm{~m}$ de largura e $3,50 \mathrm{~m}$ de altura, com fechamento de $45^{\circ}$ e malha de monofilamento com $50 \%$ de sombreamento, além de contar com estrutura de aço galvanizado. A disposição longitudinal da casa de vegetação era na posição "Leste-Oeste". 
Como substrato utilizou-se ramas de mandioca obtidas em propriedade próxima ao local do experimento, após a colheita das raízes tuberosas. As ramas foram trituradas em moinho tipo martelo, modelo TRF 650 (TRAPP), com peneira de $8 \mathrm{~mm}$, e submetidas a compostagem em estrutura de alvenaria com cobertura, com pilha de resíduos de aproximadamente $30 \mathrm{~cm}$ de altura. Durante a compostagem o material foi revirado e umedecido, sendo coletados dados de temperatura no interior do composto nos horários de 09:00h, 12:00h e 15:00h, dos quais obteve-se uma média diária e, posteriormente, semanal (Figura 1).

Figura 1. Temperatura $\left({ }^{\circ} \mathrm{C}\right)$ do substrato durante o período de compostagem das ramas de mandioca trituradas. Universidade Estadual de Mato Grosso do Sul, Aquidauana MS, 2012.

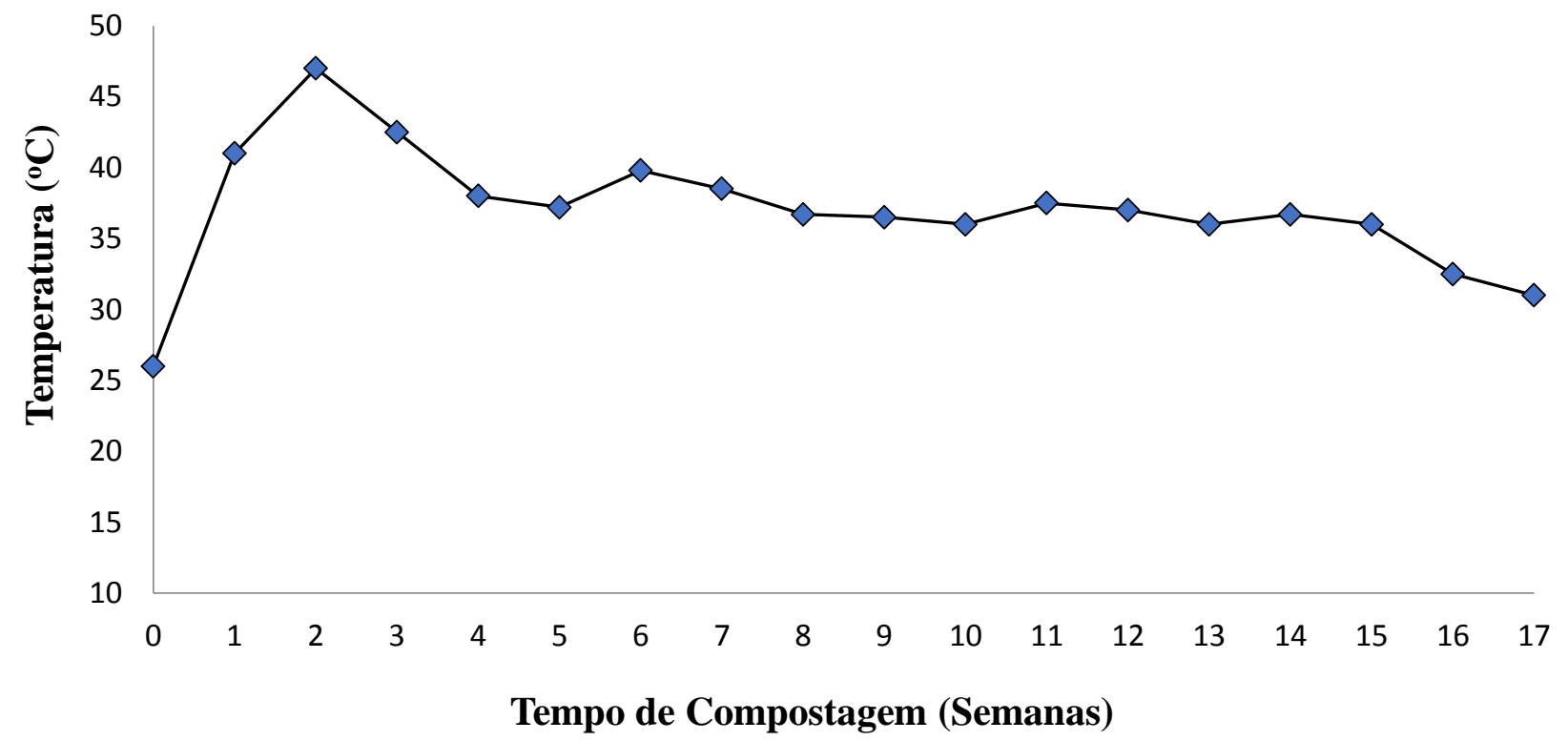

Assim, a cada 30 dias, foram retirados $70 \mathrm{~L}$ do substrato composto, que foi disposto ao sol por dois dias para redução da umidade e armazenado para preenchimento das bandejas na semeadura. Nos substratos foram adicionados $2,50 \mathrm{~kg}$ de Superfosfato Simples (18\% de $\mathrm{P}_{2} \mathrm{O}_{5}$ ), $0,30 \mathrm{~kg}$ de Cloreto de Potássio $\left(60 \%\right.$ de $\mathrm{K}_{2} \mathrm{O}$ ) e $1,50 \mathrm{~kg}$ de calcário dolomítico (100\% de PRNT) por $\mathrm{m}^{3}$ de substrato (RIBEIRO et al., 1999).

A semeadura foi realizada em setembro de 2012, em profundidade aproximada de $2,5 \mathrm{~cm}$, utilizando-se duas sementes por célula em cada tratamento, realizando desbaste das plantas menos vigorosas no $20^{\circ}$ dia após a semeadura (DAS). As bandejas foram irrigadas por rega manual (regador), três vezes ao dia (07:00, 12:00 e 16:00 h), a fim de manter o substrato com umidade constante. Foram coletadas temperaturas de bulbo seco e úmido do ambiente protegido nos horários de 09:00, 12:00 e 15:00 $\mathrm{h}$ durante o período de condução do experimento. Posteriormente foi obtida a média de umidade relativa do ar a partir do programa computacional PsychrometricFunction Demo (Tabela 1).

Tabela 1. Temperatura média $\left({ }^{\circ} \mathrm{C}\right)$ em bulbo seco e úmido e umidade relativa média (\%) nos horários 09:00, 12:00 e 15:00 h em ambiente protegido durante a condução do experimento. Universidade Estadual de Mato Grosso do Sul. Aquidauana, MS, setembro de 2012

\begin{tabular}{lccc}
\hline Horário & TBS & TBU & URA \\
\hline $09 \mathrm{~h}$ & 27,9 & 20,9 & 70 \\
$12 \mathrm{~h}$ & 34,8 & 22,9 & 65 \\
$15 \mathrm{~h}$ & 31,6 & 23 & 63 \\
\hline
\end{tabular}

$\mathrm{TBS}=$ temperatura de bulbo seco $\left({ }^{\circ} \mathrm{C}\right) ; \mathrm{TBU}=$ temperatura de bulbo úmido $\left({ }^{\circ} \mathrm{C}\right) ; \mathrm{UR}=$ umidade relativa $(\%)$. 
A partir da emergência das plântulas, iniciou-se avaliação do índice de velocidade de emergência (IVE) (MAGUIRE, 1962; PIRE; VARGAS-SIMON, 2019) e a porcentagem de emergência (PE). Os dados foram coletados diariamente até a estabilização das emergências, ocorrida aos 18 dias após a semeadura (DAS).

Aos 30 DAS foram avaliadas, aleatoriamente, em dez mudas de cada repetição: altura de plantas em $\mathrm{cm}(\mathrm{AP})$, utilizando régua graduada; diâmetro de caule em $\mathrm{mm}$ na região do colo da planta (DC), com paquímetro digital; razão altura/diâmetro (RAD); comprimento do sistema radicular em cm (CSR), com régua graduada; massa seca da parte aérea em g (MSPA), massa seca das raízes em g (MSR) e massa seca total em g (MST). Para avaliação da massa seca, separou-se a parte aérea das raízes de cada muda, e posteriormente realizou-se secagem em estufa de ventilação forçada, a 65 ${ }^{\circ} \mathrm{C}$, em sacos de papel previamente identificados, até atingirem massa constante, procedendo às respectivas pesagens das amostras em balança analítica eletrônica $(0,001 \mathrm{~g})$. Para obtenção da MST realizou-se a somatória das médias de MSPA e MSR de cada tratamento.

A partir dos dados obtidos, foi aferido o índice de qualidade de Dickson (IQD), determinado em função da altura da parte aérea $(A P)$, do diâmetro do caule (DC), da matéria seca da parte aérea (MSPA), matéria seca das raízes (MSR) e matéria seca total (MST), por meio da fórmula de Dickson et al. (1960):

$$
\mathrm{IQD}=\frac{\mathrm{MST}(\mathrm{g})}{\mathrm{AP}(\mathrm{cm}) / \mathrm{DC}(\mathrm{mm})+\mathrm{MSPA}(\mathrm{g}) / \mathrm{MSR}(\mathrm{g})}
$$

Os dados foram submetidos à análise de variância e, ao ser constatado a significância pelo teste $F$, as médias das cultivares foram comparadas pelo teste de Tukey ao nível de significância de $5 \%$. Para os tempos de compostagem foi realizada regressão. Todas as análises estatísticas foram realizadas pelo programa estatístico Sisvar (FERREIRA, 2011). Havendo interações significativas entre os fatores, foram realizados os respectivos desdobramentos.

\section{Resultados e Discussão}

Entre os componentes avaliados para a produção de mudas de melão, apenas a massa seca de raízes (MSR) não foi influenciada significativamente $(P>0,05)$ pelos períodos de compostagem do substrato. Para a comparação entre cultivares, apenas o índice de velocidade de emergência (IVE) e a porcentagem de emergência (PE) não apresentaram respostas significativas. Houve ainda interações entre os períodos de compostagem do substrato $e$ as cultivares testadas $(\mathrm{P} \times \mathrm{C})$ para todas as características (Tabela 2).

Tabela 2.Valores de $\mathrm{F}$ calculado para as características índice de velocidade de emergência (IVE), porcentagem de emergência (PE), altura de plântulas ( $A P$ ), diâmetro de caules (DC), razão altura/diâmetro (RAD), comprimento do sistema radicular (CSR), massa seca de parte aérea (MSPA), massa seca de raízes (MSR), massa seca total (MST) e índice de qualidade de Dickson (IQD) em mudas de melão cultivado em ambiente protegido. Universidade Estadual de Mato Grosso do Sul. Aquidauana, MS, 2012

\begin{tabular}{lcccccccccc}
\hline FV & IVE & PE & AP & DC & RAD & CSR & MSPA & MSR & MST & IQD \\
\hline P & $19,40^{*}$ & $15,10^{*}$ & $9,90^{*}$ & $14,80^{*}$ & $5,90^{*}$ & $36,20^{*}$ & $34,80^{*}$ & $3,00^{\text {ns }}$ & $18,90^{*}$ & $9,20^{*}$ \\
C & $11,00^{\text {ns }}$ & $14,20^{\text {ns }}$ & $281,10^{*}$ & $64,00^{*}$ & $147,60^{*}$ & $49,50^{*}$ & $91,30^{*}$ & $29,81^{*}$ & $84,90^{*}$ & $95,70^{*}$ \\
P x C & $30,60^{*}$ & $24,50^{*}$ & $10,90^{*}$ & $11,60^{*}$ & $9,50^{*}$ & $30,20^{*}$ & $10,30^{*}$ & $3,00^{*}$ & $7,80^{*}$ & $14,70^{*}$ \\
\hline MG & 1,43 & 56,72 & 5,18 & 2,28 & 2,24 & 7,13 & 0,04 & 0,02 & 0,06 & 0,01 \\
\hline CV & 25,75 & 23,41 & 15,33 & 10,44 & 14,21 & 8,53 & 28,38 & 30,00 & 29,42 & 17,93 \\
\hline
\end{tabular}

FV: Fontes de variação; P: Período de compostagem; C: Cultivares; P x C: interação entre período de compostagem e cultivares; MG: Média Geral; CV: Coeficiente de Variação (\%) *: significativo a 5\%; ${ }^{\text {ns }}$ : não significativo. 
As cultivares de melão responderam de forma significativa ao tempo de compostagem do substrato para o índice de velocidade de emergência (IVE) e a porcentagem de emergência $(P E)$, havendo ainda interação significativa entre os fatores $(\mathrm{P} \times \mathrm{C})$ para ambas as características. Para a cultivar Gaúcho Casca de Carvalho, o tempo de compostagem do substrato proporcionou um modelo quadrático, com ponto de máxima IVE estimado em 2,25 plântulas dia ${ }^{-1}$, correspondente a 25 dias de compostagem do substrato. Comportamento semelhante foi observado para a PE, cujo ponto de máxima $\mathrm{PE}$ estimado foi de $80,15 \%$, correspondente ao período de 29 dias de compostagem (Figura 2). A cultivar Melão amarelo, por sua vez, não se ajustou de forma significativa a regressão para ambas as variáveis resposta (Tabela 2).

Figura 2. Índice de velocidade de emergência (plântulas dia $^{-1}$ ) e porcentagem de emergência (\%) de plântulas de melão das cultivares Gaúcho Casca de Carvalho (GCC) e Melão Amarelo (MA) em função do tempo de compostagem de ramas de mandioca trituradas (substrato). Universidade Estadual de Mato Grosso do Sul. Aquidauana, MS, 2012.

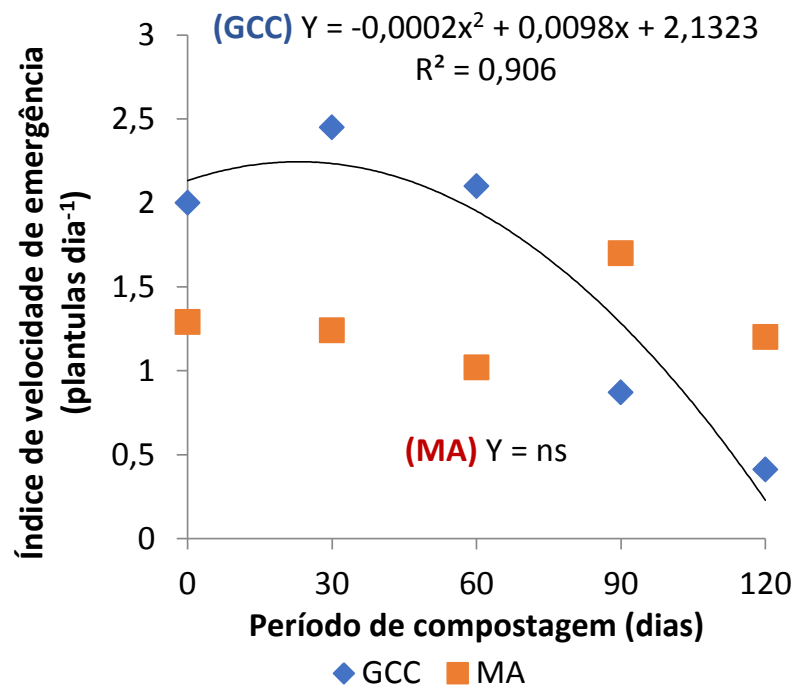

A redução ocorrida para a germinação de plântulas em função dos períodos mais prolongados de compostagem pode estar relacionada principalmente à maior capacidade de retenção de água proporcionada por estes substratos, o que tende a reduzir a disponibilidade de oxigênio durante o processo germinativo (OLIVEIRA et al., 2005; CAMARGO et al., 2011).

Por sua vez, realizando o desdobramento para as cultivares de melão, em todos os níveis de compostagem do substrato, observaram-se diferenças significativas para o IVE, possibilitando constatar que a cultivar Gaúcho Casca de Carvalho apresentou valores superiores de IVE em relação a cultivar Melão Amarelo para os períodos de 0,30 e 60 dias, entretanto, nos períodos de 90 e 120 dias de compostagem a cultivar Melão Amarelo foi superior para essa

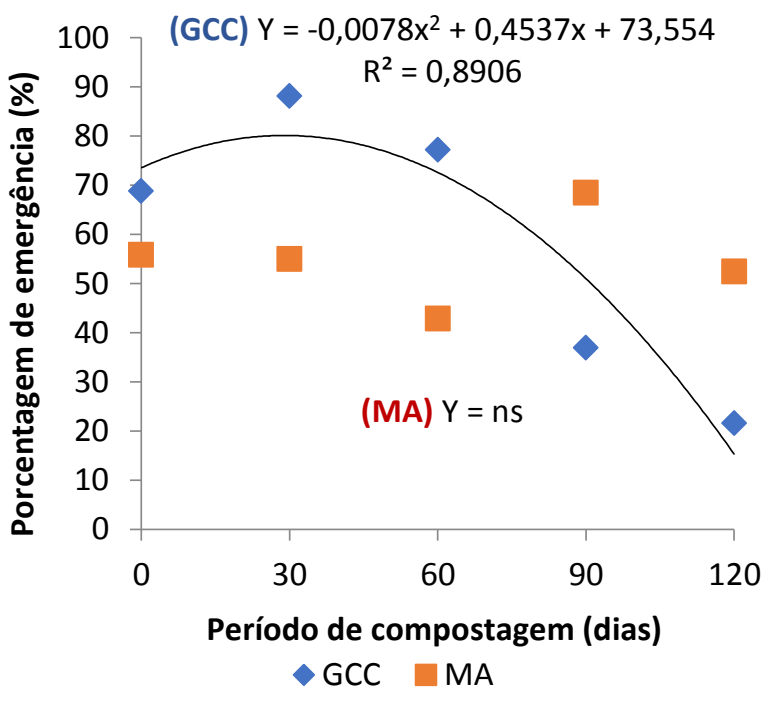

variável. Para a PE verificou-se diferença significativa entre as cultivares a partir dos 30 dias do período de compostagem. A cultivar Gaúcho Casca de Carvalho apresentou maiores valores médios de emergência até os 60 dias de compostagem quando comparada a cultivar Melão Amarelo, cuja PE aumentou significativamente a partir dos 90 dias do período avaliado (Tabela 3).

É oportuno ressaltar o exposto por Oliveira et al., (1998), que avaliando a germinação de sementes de melão em condições de estresse salino, obtiveram respostas germinativas distintas para cultivares, evidenciando que cada material genético pode responder de forma diferente quando semeados em condições semelhantes. 
Tabela 3. Desdobramento para o índice de velocidade de emergência (plântulas/dia) e porcentagem de germinação (\%) de plântulas das cultivares de melão Gaúcho Casca de Carvalho (GCC) e Melão Amarelo (MA) em função do período de compostagem de ramas de mandioca trituradas (substrato). Universidade Estadual de Mato Grosso do Sul. Aquidauana, MS, 2012

\begin{tabular}{|c|c|c|c|c|c|}
\hline \multirow[t]{2}{*}{ Cultivar } & \multicolumn{5}{|c|}{ Períodos de Compostagem (dias) } \\
\hline & 0 & 30 & 60 & 90 & 120 \\
\hline & \multicolumn{5}{|c|}{ Índice de velocidade de emergência (plântulas dia ${ }^{-1}$ ) } \\
\hline GCC & $2,00 \mathrm{Aa}$ & $2,45 \mathrm{Aa}$ & $2,10 \mathrm{Aa}$ & $0,87 \mathrm{Bb}$ & $0,41 \mathrm{Bb}$ \\
\hline \multirow[t]{2}{*}{ MA } & $1,29 \mathrm{ABb}$ & $1,24 \mathrm{ABb}$ & $1,02 \mathrm{Bb}$ & $1,70 \mathrm{Aa}$ & $1,20 \mathrm{ABa}$ \\
\hline & \multicolumn{5}{|c|}{ Porcentagem de germinação (\%) } \\
\hline GCC & $68,8 \mathrm{Ba}$ & $88,1 \mathrm{Aa}$ & $77,2 \mathrm{ABa}$ & $36,9 \mathrm{Cb}$ & $21,6 \mathrm{Cb}$ \\
\hline MA & $55,8 \mathrm{ABa}$ & $55,0 \mathrm{ABb}$ & $42,9 \mathrm{Bb}$ & $68,5 \mathrm{Aa}$ & $52,4 \mathrm{ABa}$ \\
\hline
\end{tabular}

*Médias seguidas por letras maiúsculas e minúsculas iguais nas linhas e colunas, respectivamente, não diferem entre si pelo Teste de Tukey a $5 \%$ de probabilidade

Avaliando cultivares de pimentão, Costa et al., (2013) verificaram que o menor IVE das plântulas foi obtido em substrato constituído por $100 \%$ de rama de mandioca em comparação a substratos mistos. Os mesmos relataram ainda que isso se deve, provavelmente, pela alta relação entre carbono e nitrogênio $(C / N)$ do substrato. Entretanto, os autores obtiveram respostas evidenciando que tal comportamento ocorre de forma diferente para cada cultivar analisado, sugerindo que o mesmo deve ocorrer para diferentes culturas.

Os resultados obtidos para a germinação e emergência das mudas corroboram ainda com diversos autores, que verificaram diferenças para tal em função da utilização de ramas de mandioca como substrato (COSTA et al., 2013; LUQUI et al., 2015). É importante frisar que a germinação rápida e uniforme de sementes, seguida por imediata emergência de plântulas, são características desejáveis na produção de mudas (MARTINS et al., 1999).

Com relação aos dados de altura de plantas (AP) e diâmetro do colo (DC), foram observadas respostas significativas para ambas as cultivares em função do tempo de compostagem do substrato, havendo ainda interação significativa entre os fatores ( $P \times C$ ) para ambas as características. Assim, para a AP da cultivar Melão Amarelo, o tempo de compostagem do substrato proporcionou um modelo quadrático, com ponto de mínima AP estimado em 5,96 cm, correspondente à compostagem do substrato realizada por 47 dias (Figura 3). No que diz respeito ao $D C$, o comportamento observado foi cúbico, havendo decréscimo das médias até o período de 30 dias de compostagem, com posterior elevação até o período de 90 dias, quando novamente passou a ocorrer decréscimo, assim o comportamento da cultivar em função dos dias de compostagem do substrato pode ser melhor descrito pelo teste de comparação de médias (Tabela 4). A cultivar Gaúcho Casca de Carvalho não teve seus dados ajustados de forma significativa a regressão para a AP e DC (Figura 3).

Para a razão média de altura/diâmetro do colo (RAD), que expressa o equilíbrio de desenvolvimento da muda a partir de um único índice de parâmetros (CRUZ et. al., 2006) e para o comprimento do sistema radicular (CSR) verificaram-se diferenças entre os fatores avaliados, havendo ainda interação significativa entre os mesmos para ambas as variáveis resposta. Assim, para a RAD, a cultivar Gaúcho Casca de Carvalho apresentou comportamento quadrático em função dos períodos de compostagem do substrato, com ponto de máxima resposta estimada de $1,97 \mathrm{~cm} \mathrm{~mm}^{-1}$, correspondente à compostagem do substrato por 51 dias. Enquanto isso, a cultivar Melão Amarelo apresentou comportamento quadrático distinto, com ponto de mínima RAD estimada de $2,49 \mathrm{~cm}$ $\mathrm{mm}^{-1}$, correspondente à compostagem do substrato por 47 dias (Figura 3). Tais resultados indicam que o equilíbrio de desenvolvimento das mudas apresenta respostas que tendem a variar conforme a cultivar de melão utilizada. Por sua vez, para o CSR, a cultivar Gaúcho Casca de Carvalho apresentou comportamento quadrático em função dos períodos de compostagem, com ponto de máximo CSR estimado de $8,62 \mathrm{~cm}$, referente à compostagem realizada por 95 dias. Para a cultivar Melão Amarelo, não houve ajuste das médias a regressão para o CSR (Figura 3). 
Figura 3. Altura de Plantas $(\mathrm{cm})$, diâmetro de caules $(\mathrm{mm})$, razão média de altura/diâmetro do colo (cm $\mathrm{mm}^{-1}$ ) e comprimento do sistema radicular $(\mathrm{cm})$ em plântulas de melão das cultivares Gaúcho Casca de Carvalho (GCC) e Melão Amarelo (MA) em função do tempo de compostagem de ramas de mandioca trituradas (substrato). Universidade Estadual de Mato Grosso do Sul. Aquidauana, MS, 2012.
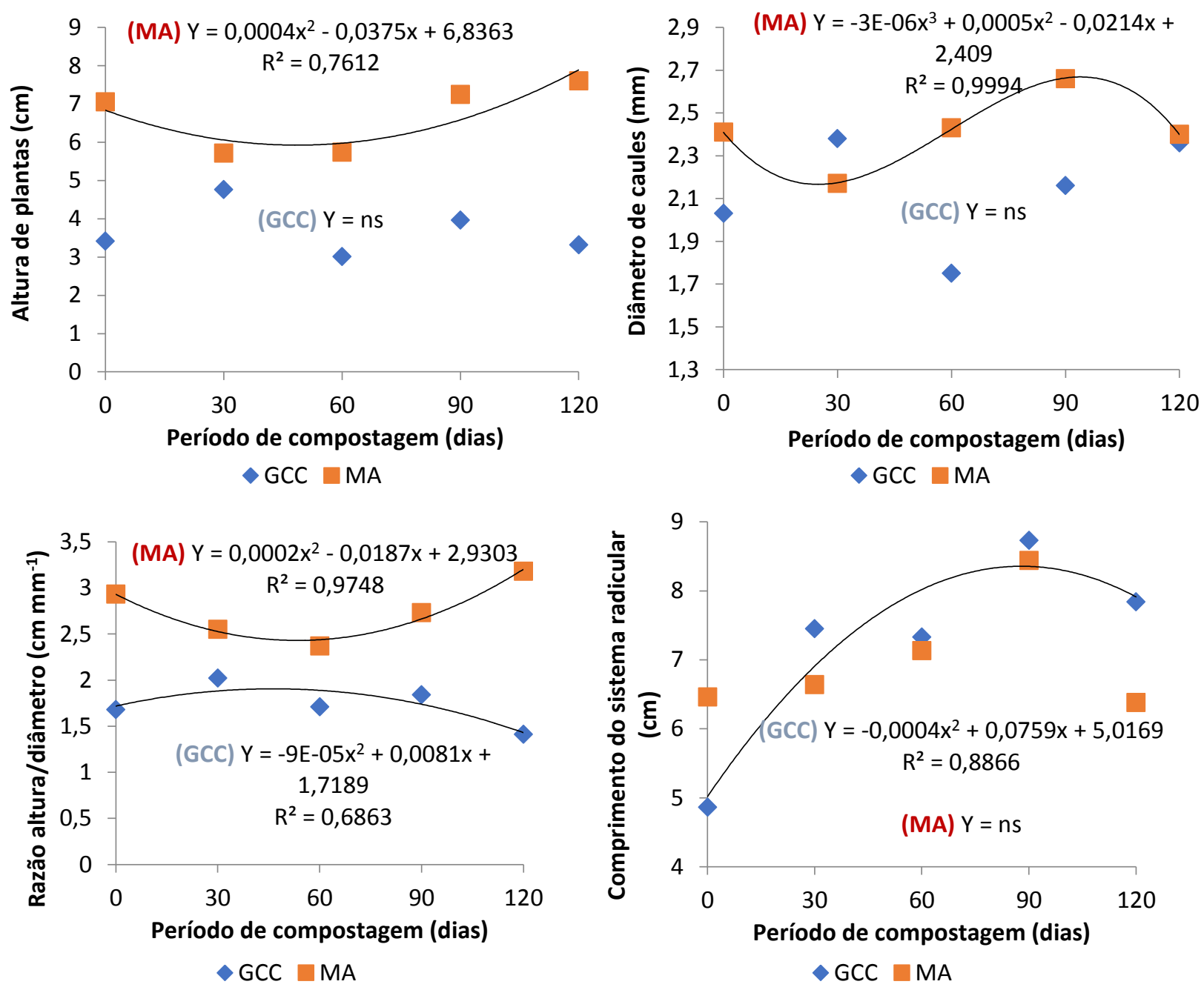

No que diz respeito a $\mathrm{AP}$, observou-se que a cultivar Melão Amarelo apresentou maiores valores médios quando comparada à Gaúcho Casca de Carvalho, independentemente do período de compostagem do substrato, alcançando altura máxima quando cultivada em substratos com 0, 90 e 120 dias de compostagem, não diferindo estatisticamente entre os três períodos. Para a cultivar Gaúcho Casca de Carvalho, os maiores valores de AP foram obtidos quando a cultivar foi semeada em substratos com 30 e 90 dias de compostagem (Tabela 4). Por sua vez, para o DC, com exceção dos períodos de compostagem de 30 e 120 dias, a cultivar Melão Amarelo também apresentou valores médios superiores à Gaúcho Casca de Carvalho. Quando avaliada individualmente, a cultivar Gaúcho Casca

de Carvalho apresentou os maiores valores de DC quando semeada em substratos com 30, 90 e 120 dias de compostagem, enquanto que a cultivar Melão Amarelo apresentou valores superiores de DC a partir dos substratos obtidos com 0, 60, 90 e 120 dias de compostagem das ramas de mandioca (Tabela 4).

Desdobrando-se as médias obtidas para cada substrato e ambas as cultivares, a menor RAD foi obtida para a cultivar de melão Gaúcho Casca de Carvalho, semeado em substrato com 120 dias de compostagem $\left(1,41 \mathrm{~cm} \mathrm{~m}{ }^{-1}\right)$, ficando $1,77 \mathrm{~cm} \mathrm{~mm}^{-1}$ aquém da maior relação, obtida para a cultivar Melão Amarelo em substrato semelhante (Tabela 4), podendo indicar que o principal fator que tende a influenciar a variável resposta é a cultivar semeada. 
Para o CSR observou-se que a cultivar de melão Gaúcho Casca de Carvalho apresentou maiores médias proporcionadas pelos tratamentos com 90 e 120 dias de compostagem. Por sua vez, a cultivar Melão Amarelo apresentou valores mais elevados para o CSR quando semeada em substrato com 90 dias de compostagem (Tabela 4). Comparando as cultivares, foi possível observar que a Gaúcho
Casca de Carvalho apresentou maior CSR a partir dos 30 dias de compostagem em relação a cultivar Melão Amarelo, exceto para os tratamentos cuja compostagem durou 60 e 90 dias, onde as médias se igualaram estatisticamente.

Tabela 4. Desdobramento para a altura de plantas $(\mathrm{cm})$, diâmetro de colos $(\mathrm{mm})$, razão média de altura/diâmetro do colo $\left(\mathrm{cm} \mathrm{mm}^{-1}\right)$ e comprimento do sistema radicular $(\mathrm{cm})$ em plântulas das cultivares de melão Gaúcho Casca de Carvalho (GCC) e Melão Amarelo (MA) em função do período de compostagem de ramas de mandioca trituradas (substrato). Universidade Estadual de Mato Grosso do Sul. Aquidauana, MS, 2012

\begin{tabular}{|c|c|c|c|c|c|}
\hline \multirow[t]{2}{*}{ Cultivar } & \multicolumn{5}{|c|}{ Períodos de Compostagem (dias) } \\
\hline & 0 & 30 & 60 & 90 & 120 \\
\hline & \multicolumn{5}{|c|}{ Altura de plantas $(\mathrm{cm})$} \\
\hline GCC & $3,41 \mathrm{Bb}$ & $4,76 \mathrm{Ab}$ & $3,01 \mathrm{Cb}$ & $3,96 \mathrm{ABb}$ & $3,32 \mathrm{Bb}$ \\
\hline \multirow[t]{2}{*}{ MA } & $7,05 \mathrm{Aa}$ & $5,71 \mathrm{Ba}$ & $5,74 \mathrm{Ba}$ & $7,25 \mathrm{Aa}$ & $7,60 \mathrm{Aa}$ \\
\hline & \multicolumn{5}{|c|}{ Diâmetro de colo (mm) } \\
\hline GCC & $2,03 \mathrm{BCb}$ & $2,38 \mathrm{Aa}$ & $1,75 \mathrm{Cb}$ & $2,16 \mathrm{ABb}$ & $2,36 \mathrm{Aa}$ \\
\hline \multirow[t]{2}{*}{ MA } & $2,41 \mathrm{ABa}$ & $2,17 \mathrm{Ba}$ & $2,43 \mathrm{ABa}$ & $2,66 \mathrm{Aa}$ & $2,40 \mathrm{ABa}$ \\
\hline & \multicolumn{5}{|c|}{ Razão média de altura/diâmetro de colos $\left(\mathrm{cm} \mathrm{mm}^{-1}\right)$} \\
\hline GCC & $1,68 \mathrm{ABb}$ & $2,02 \mathrm{Ab}$ & $1,71 \mathrm{ABb}$ & $1,84 \mathrm{ABb}$ & $1,41 \mathrm{Bb}$ \\
\hline \multirow[t]{2}{*}{ MA } & $2,93 \mathrm{ABa}$ & $2,55 \mathrm{BCa}$ & $2,37 \mathrm{Ca}$ & $2,73 \mathrm{Ba}$ & $3,18 \mathrm{Aa}$ \\
\hline & \multicolumn{5}{|c|}{ Comprimento do sistema radicular $(\mathrm{cm})$} \\
\hline GCC & $4,86 \mathrm{Cb}$ & 7,45 Ba & 7,33 Ba & $8,73 \mathrm{Aa}$ & 7,84 ABa \\
\hline MA & $6,46 \mathrm{Ba}$ & $6,64 \mathrm{Bb}$ & $7,13 \mathrm{Ba}$ & $8,44 \mathrm{Aa}$ & $6,38 \mathrm{Bb}$ \\
\hline
\end{tabular}

*Médias seguidas por letras maiúsculas e minúsculas iguais nas linhas e colunas, respectivamente, não diferem entre si pelo Teste de Tukey a $5 \%$ de probabilidade

Diversos autores relacionam incrementos à AP e ao DC em decorrência da utilização de substratos contendo compostos orgânicos ao suprimento de nutrientes proporcionado pelos mesmos (CAMARGO et al., 2011), tal como pelas características físicas apresentadas (LIMA et al., 2006). Assim, alterações em ambas as características das mudas tendem a estar relacionadas às características nutricionais do substrato, associando-se diretamente com a elevada relação $\mathrm{C} / \mathrm{N}$ do material.

Os valores médios de AP e DC obtidos no presente estudo corroboram com aqueles observados por Araújo et al. (2013), que avaliaram produção de mudas de melão Cantaloupe em diferentes tipos de substratos. Os valores obtidos pelos autores variaram entre aproximadamente 2 e $8 \mathrm{~cm}$ para a AP e aproximadamente 2 a $4 \mathrm{~mm}$ para $\mathrm{O} \mathrm{DC}$. Luquiet al. (2015), avaliando a influência de substratos a base de combinações com vermiculita, estercos bovino e de aves, e ramas de mandioca trituradas sobre o desenvolvimento de mudas de pepino, observaram menor AP e DC quando utilizaram mistura contendo ramas de mandioca.

Os valores obtidos para a RAD relacionamse diretamente àqueles observados para a $A P$ e para o DC, sendo que quanto maior a altura das plantas e menor o diâmetro das mesmas, maiores são os valores de RAD. A importância da AP e do $D C$ se relaciona com o transporte e acúmulo de nutrientes e suporte das plântulas. Sendo assim, mudas com valores baixos de DC tendem a se desenvolver menos, além de poderem sofrer tombamentos ou apresentar perdas e deformações.

De forma análoga ao ocorrido para a cultivar Gaúcho Casca de Carvalho no presente 
estudo, Medeiros et al., (2018), avaliando a utilização de substratos alternativos na produção de mudas de pepino, não observaram diferenças significativas na RAD para a cultura em função dos substratos, independentemente da utilização ou não de compostos orgânicos na composição dos mesmos. Em contraste, a mesma tendência não foi observada para a cultivar Melão Amarelo.

O CSR relaciona-se diretamente com a densidade do substrato e, consequentemente, a aeração proporcionada pelo mesmo (MINAMI et al., 2000; FACHINELLO et al., 2005), além de apresentar comportamentos distintos para diferentes cultivares de meloeiro (SILVA JÚNIOR et al., 2018). Nesse contexto, é oportuno ressaltar que o desenvolvimento adequado do sistema radicular infere que, depois de transplantadas, as mudas apresentarão maior capacidade de absorver água e nutrientes, garantindo melhor desenvolvimento da cultura (VENDRUSCOLO et al., 2016).

Com relação aos resultados de massa seca de parte aérea (MSPA) e massa seca de raízes (MSR) das mudas, foram observadas respostas significativas para ambas as cultivares em função do tempo de compostagem do substrato, havendo ainda interação significativa entre os fatores para ambas as características. Assim, para ambas as cultivares, os dados de MSPA ajustaram-se ao modelo quadrático da regressão, apresentando ponto de mínima MSPA de 0,02 g para o período de 50 dias de compostagem e 0,03 g para o período de 42 dias para as cultivares Gaúcho Casca de Carvalho e Melão Amarelo, respectivamente. A partir dos períodos mencionados, houve acréscimos a MSPA até o período de 120 dias de compostagem, para ambas as cultivares (Figura 4). De forma análoga, para a MSR, ambas as cultivares responderam de forma quadrática aos períodos de compostagem do substrato avaliados, assim, para a cultivar Melão Casca de Carvalho, observou-se ponto de mínima MSR estimada em 0,008 g, referente ao período de 33 dias de compostagem do substrato, enquanto que, para a cultivar Melão Amarelo, o ponto de mínima MSR, estimada em $0,014 \mathrm{~g}$, referiu-se ao período de 67 dias de compostagem (Figura 4).

As cultivares de melão responderam de forma significativa ao tempo de compostagem do substrato para a massa seca total (MST) e ao índice de qualidade de Dickson (IQD), havendo interação significativa entre os fatores para ambas as características. Os dados de MST ajustaram-se ao modelo quadrático da regressão para ambas as cultivares, apresentando ponto de mínima MST de 0,03 g para o período de 45 dias de compostagem e 0,045 g para o período de 50 dias, para as cultivares Gaúcho Casca de Carvalho e Melão Amarelo, respectivamente. A partir dos períodos mencionados, houve acréscimos a MSPA para ambas as cultivares até o período de 120 dias, onde foi atingida a máxima resposta observada (Figura 4).

Comportamento semelhante foi observado para a IQD para a cultivar Gaúcho Casca de Carvalho, cujo ponto de máximo IQD estimado foi de 0,014, correspondente ao período de 120 dias de compostagem do substrato. A cultivar Melão amarelo, por sua vez, ajustou-se ao modelo cúbico à regressão (Figura 4). 
Figura 4. Massa seca da parte aérea (g), massa seca de raízes (g), massa seca total (g) e índice de qualidade de Dickson em plântulas de melão das cultivares Gaúcho Casca de Carvalho (GCC) e Melão Amarelo (MA) em função do tempo de compostagem de ramas de mandioca trituradas (substrato). Universidade Estadual de Mato Grosso do Sul. Aquidauana, MS, 2012.
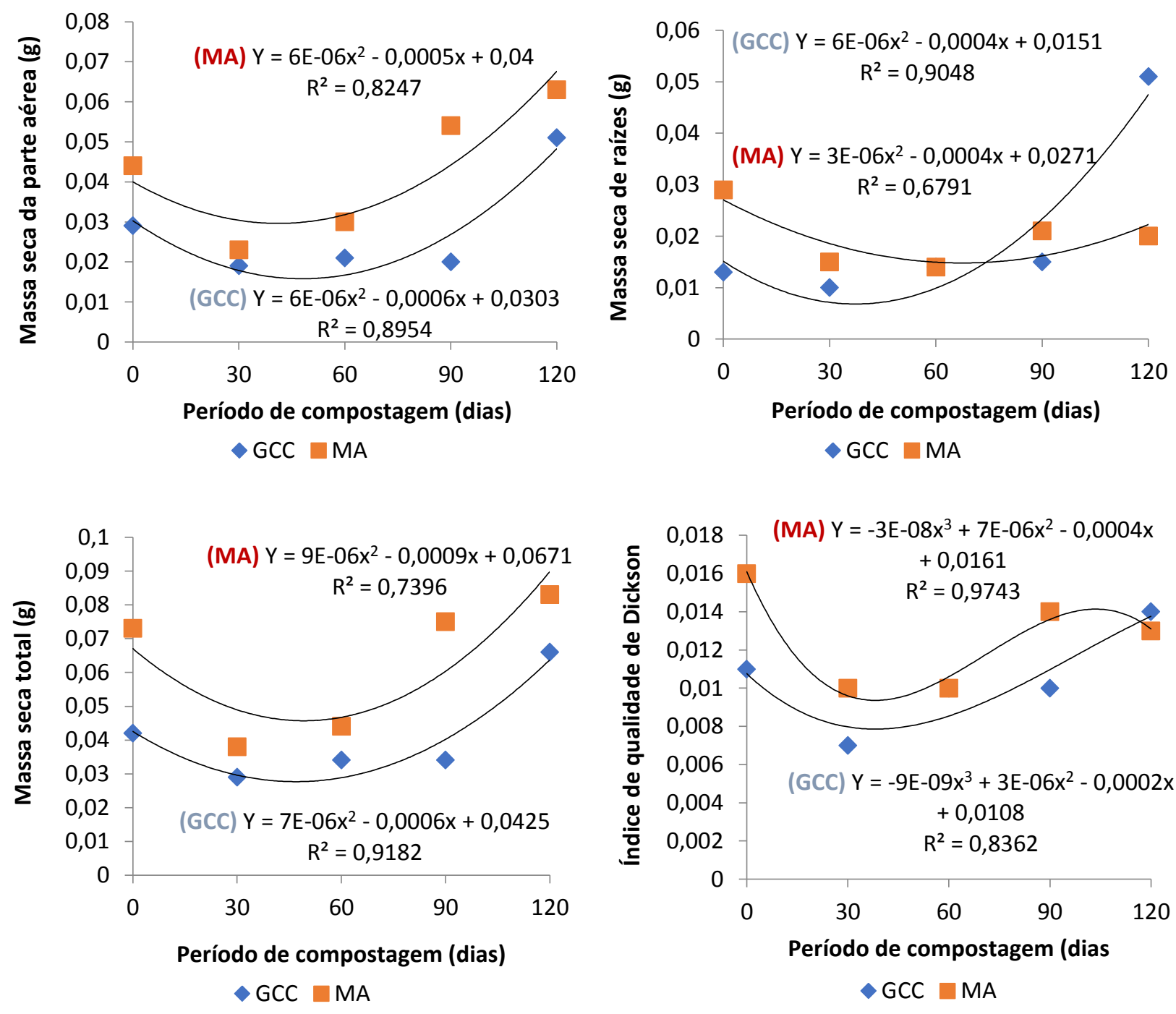

Com o desdobramento do fator cultivar foi possível constatar que, com exceção do substrato produzido com 30 dias de compostagem, foram observadas diferenças significativas entre as cultivares de melão para a MSPA em todos os demais níveis de compostagem, com valores superiores para a cultivar Melão Amarelo (Tabela 5). Para a cultivar Gaúcho Casca de Carvalho, foram observados valores superiores de MSPA para o substrato produzido com 120 dias de compostagem. Em contrapartida, para a produção de mudas da cultivar Melão Amarelo, os melhores resultados para a variável foram observados com a compostagem realizada por 90 e 120 dias (Tabela 5). Assim, os resultados obtidos para ambas as cultivares evidenciam que a compostagem das ramas por maiores períodos

de tempo pode favorecer o acumulo de MSPA em mudas de melão.

No que diz respeito à MSR para a cultivar Gaúcho Casca de Carvalho, verificou-se média superior para o período de 120 dias de compostagem e, para a cultivar Melão Amarelo, o substrato que não passou pela compostagem ( 0 dias) apresentou valor superior de MSR, porém, não diferindo dos períodos de 90 e 120 dias (Tabela 5).

Ao realizar o desdobramento para a MST em resposta ao tempo de compostagem, verificou-se que a cultivar Gaúcho Casca de Carvalho apresentou valores superiores quando utilizado substrato após 120 dias de compostagem (Tabela 5). A cultivar Melão Amarelo apresentou maiores valores para a MST 
nos períodos de 0, 90 e 120 dias entre os períodos de compostagem avaliados. De modo geral, com exceção do período de 30 dias de compostagem, essa cultivar apresentou maiores valores de MST em relação a cultivar Gaúcho Casca de Carvalho.

Para o IQD, verificou-se efeito significativo para as cultivares avaliadas no período inicial de compostagem ( 0 dias) e aos 90 dias, onde a cultivar Melão Amarelo apresentou valor médio superior de IQD. Para essa cultivar a ausência de compostagem (0 dias) apresentou valores superiores de IQD, entretanto, tais valores não diferiram estatisticamente dos períodos de 90 e 120 dias de compostagem. Em relação ao período de compostagem das ramas, para a cultivar Gaúcho Casca de Carvalho, o período de compostagem de 120 dias apresentou valor superior para a variável resposta, não diferindo, entretanto, dos tratamentos compostos pelos períodos de 0,60 e 90 dias que (Tabela 5).

Tabela 5. Desdobramento para a massa seca da parte aérea $(\mathrm{g})$, massa seca de raízes (g), massa seca total (g) e índice de qualidade de Dickson em plântulas das cultivares de melão Gaúcho Casca de Carvalho (GCC) e Melão Amarelo (MA) em função do período de compostagem de ramas de mandioca trituradas (substrato). Universidade Estadual de Mato Grosso do Sul. Aquidauana, MS, 2012

\begin{tabular}{|c|c|c|c|c|c|}
\hline \multirow[t]{2}{*}{ Cultivar } & \multicolumn{5}{|c|}{ Períodos de Compostagem (dias) } \\
\hline & 0 & 30 & 60 & 90 & 120 \\
\hline & \multicolumn{5}{|c|}{ Massa seca da parte aérea (g) } \\
\hline GCC & $0,029 \mathrm{Bb}$ & 0,019 Ba & $0,021 \mathrm{Ba}$ & $0,020 \mathrm{Bb}$ & $0,051 \mathrm{Ab}$ \\
\hline \multirow[t]{2}{*}{ MA } & 0,044 Ba & $0,023 \mathrm{Ca}$ & 0,030 Ca & $0,054 \mathrm{ABa}$ & $0,063 \mathrm{Aa}$ \\
\hline & \multicolumn{5}{|c|}{ Massa seca de raízes (g) } \\
\hline GCC & $0,013 \mathrm{Ab}$ & $0,010 \mathrm{Aa}$ & $0,013 \mathrm{Aa}$ & $0,014 \mathrm{Aa}$ & $0,015 \mathrm{Aa}$ \\
\hline \multirow[t]{2}{*}{ MA } & $0,029 \mathrm{Aa}$ & $0,015 \mathrm{Ba}$ & $0,014 \mathrm{Ba}$ & $0,021 \mathrm{ABa}$ & $0,020 \mathrm{ABa}$ \\
\hline & \multicolumn{5}{|c|}{ Massa seca total (g) } \\
\hline GCC & $0,042 \mathrm{Bb}$ & $0,029 \mathrm{Ba}$ & 0,034 Ba & $0,034 \mathrm{Bb}$ & $0,066 \mathrm{Ab}$ \\
\hline \multirow[t]{2}{*}{ MA } & $0,073 \mathrm{Aa}$ & $0,038 \mathrm{Ba}$ & 0,044 Ba & $0,075 \mathrm{Aa}$ & $0,083 \mathrm{Aa}$ \\
\hline & \multicolumn{5}{|c|}{ Índice de qualidade de Dickson } \\
\hline GCC & $0,011 \mathrm{ABb}$ & $0,007 \mathrm{Bb}$ & $0,010 \mathrm{ABa}$ & $0,010 \mathrm{ABb}$ & $0,014 \mathrm{Aa}$ \\
\hline MA & 0,016 Aa & 0,010 Ba & 0,010 Ba & 0,014 ABa & $0,013 \mathrm{ABa}$ \\
\hline
\end{tabular}

*Médias seguidas por letras maiúsculas e minúsculas iguais nas linhas e colunas, respectivamente, não diferem entre si pelo Teste de Tukey a 5\% de probabilidade

Os resultados obtidos para MSPA e MSR podem ser explicados pelas melhorias proporcionadas pela decomposição da matéria orgânica, sobretudo em relação aos atributos físicos e químicos do substrato, tendo em vista que a aeração, o armazenamento de água, a redução na lixiviação e aumento na disponibilidade de nutrientes relacionam-se diretamente ao melhor desenvolvimento de mudas (LIMA et al., 2006; MOREIRA et al., 2018). Nesse contexto, resultados positivos proporcionados pela adição de matéria orgânica aos substratos destinados a produção de mudas de melão já foram observados por diversos autores, tais como Barros et al. (2011) e Lopes et al. (2017).

Por sua vez, o comportamento observado para a MST da cultivar Gaúcho Casca de Carvalho foi condizente com aqueles obtidos para a massa seca de parte aérea, o que se justifica pelo fato da MSPA contribuir de forma majoritária para a MST (LOPES et al., 2017). Entretanto, para a cultivar Melão Amarelo, houve maior contribuição da MSR em relação a cultivar Gaúcho Casca de Carvalho para o tratamento onde não foi realizada a compostagem do substrato, fazendo assim com que os resultados de MST apresentem comportamento proporcional àqueles obtidos para a MSR.

O IQD, por incluir relações morfológicas de AP, DC e fitomassas, indica o vigor das mudas que serão transplantadas (CRUZ, et al. 2006). Mudas bem formadas, com valores elevados de IQD, apresentam maior qualidade para transplante e, consequentemente, melhor estabelecimento e desempenho agronômico. 


\section{Conclusões}

O período de compostagem de 120 dias para ramas de mandioca trituradas (substrato), sob as condições do presente estudo, é o mais indicado para o desenvolvimento de mudas de melão das cultivares Gaúcho Casca de Carvalho e Melão Amarelo.

\section{Referências}

ARAGÃO, C.A.; PIRES, M.M.M.L.; BATISTA, P.F.; DANTAS, B.F. Qualidade de mudas de melão produzidas em diferentes substratos. Revista Caatinga, Mossoró, v. 24, n. 3, p. 209-214, 2011.

ARAÚJO, D.L.; MAIA JÚNIOR, S.O.; SILVA, S.F.; ANDRADE, J.R.; ARAÚJO, D.L. Produção de mudas de melão cantaloupe em diferentes tipos de substratos. Revista Verde de Agroecologia e Desenvolvimento Sustentável, v.8, n.3, p.15-20, 2013.

BARDIVIESSO, D.M.; MARUYAMA, W.I.; PESSATO, L.E.; PEREIRA, A.C.B; MODESTO, J.H. Adubação potássica na produção de duas cultivares de meloeiro. Revista de Agricultura Neotropical, Cassilândia, v. 2, n. 1, p. 32-40, 2015.

https://doi.org/10.32404/rean.v2i1.244

BARROS, G.L.; SILVA, G.B.P.; ALMEIDA, J.P.N.; SILVA, A.R.F.; MEDEIROS P.V.Q. Influência de diferentes tipos de substratos na germinação e Desenvolvimento inicial de melão pepino (Cucumis melo var. Cantalupensis naud.). Revista Verde, Mossoró, v.6, n.1, p. 235-239, 2011.

https://doi.org/10.18378/rvads.v6i1.501

BIASI, L.A.; BILIA, D.A.C.; SÃO JOSÉ, A.R.; FORNASIERI, J.L.; MINAMI, K. Efeito de misturas de turfas e bagaço de cana sobre a produção de mudas de maracujá e tomate. Scientia Agrícola, Piracicaba, v.52, n.2, p.239-243, 1995.

http://dx.doi.org/10.1590/S0103-

$\underline{90161995000200006}$

CALDEIRA, M.V.W.; ROSA, G.N.; FENILLI, T.A.B.; HARBS, R.M.P. Composto orgânico na produção de mudas de aroeira-vermelha. Scientia Agraria, Curitiba, v.9, n.1, p.27-33, 2008.

http://dx.doi.org/10.5380/rsa.v9i1.9898

CAMARGO, R.; PIRES, S.C.; MALDONADO, A.C.; CARVALHO, H.P.; COSTA, T.R. Avaliação de substratos para a produção de mudas de pinhãomanso em sacolas plásticas. Revista Trópica -
Ciências Agrárias e Biológicas, v.5, n.1, p.31-38, 2011. http://dx.doi.org/10.0000/rtcab.v5i1.292

CORREIA, A.C.G. SANTANA, R.C.; OLIVEIRA, M.L.R.; TITON, M.; ATAÍDE, G.M.; LEITE, F.P. Volume de substrato e idade: influência no desempenho de mudas clonais de eucalipto após replantio. Cerne, Lavras, v.19, n.2, p. 185-191, $2013 . \quad \quad$ http://dx.doi.org/10.1590/S0104$\underline{77602013000200002}$

COSTA, E.; JORGE, M.H.A.; SCHWERZ, F.; CORTELASSI, J.A.S. Emergência e fitomassa de mudas de pimentão em diferentes substratos. Revista Brasileira de Ciências Agrárias, Recife, v.8, n.3, p.396-401, 2013.

http://dx.doi.org/10.5039/agraria.v8i3a2428

COSTA E.; SANTO T.L.E.; SILVA A.P.; SILVA L.E.; OLIVEIRA L.C.; BENETT C.G.S.; BENETT K.S.S. Ambientes e substratos na formação de mudas e produção de frutos de cultivares de tomate cereja. Horticultura Brasileira. Brasília, v.33, n.1, p.110-118. 2015.

http://dx.doi.org/10.1590/S0102-

$\underline{053620150000100018}$

CRUZ, C.A.F.; PAIVA, H.N.; GUERRERO, R.A. Efeito da adubação nitrogenada na produção de mudas de sete-cascas (Samanea inopinata (Harms) Ducke). Revista Árvore, Viçosa, v.30, n.4, p.537546, 2006. http://dx.doi.org/10.1590/S0100$\underline{67622006000400006}$

DICKSON, A.; LEAF, A.; HOSNER, J.F. Quality appraisal of white spruce and white pine seedling stock in nurseries. The Forest Chronicle, West Mattawa, v.36, p.10-13, 1960.

https://doi.org/10.5558/tfc36010-1

DUTRA, T.R.; MASSAD, M.D.; SARMENTO, M.F.Q.; OLIVEIRA, J.C. Emergência e crescimento inicial da canafístula em diferentes substratos e métodos de superação de dormência. Revista Caatinga, Mossoró, v.25, n.2, p.65-71, 2012.

FACHINELLO, J. C.; HOFFMANN, A.; NACHTIGAL, J. C. Propagação de plantas frutíferas. Brasília: EMBRAPA Informação Tecnológica, 2005. 221p.

FERREIRA, D.F. Sisvar: a computer statistical analysis system. Ciência e Agrotecnologia, Lavras, v.35, n.6, p.1039-1042, 2011. 
http://dx.doi.org/10.1590/S1413-

\section{$\underline{70542011000600001}$}

FILGUEIRA, F.A.R. Novo manual de Olericultura: agrotecnologia moderna na produção e comercialização de hortaliças. 3 ed. Viçosa-MG: UFV, 2013. 412p.

GOMES, L.A.A.; RODRIGUES A.C.; COLLIER L.S.; FEITOSA, S.S. Produção de mudas de alface em substrato alternativo com adubação. Horticultura Brasileira, Brasília, v.26, n.3, p.359-363, 2008. http://dx.doi.org/10.1590/S010205362008000300013

GUISOLFI, L.P.; MONACO, P.A. V.; HADDADE, I.R.; KRAUSE, M.R.; MENEGHELLI, L.A.M.; ALMEIDA, K.M. Production of cucumber seedlings in alternative substrates With different compositions of agricultural residues. Caatinga, Mossoró, v.31, n.3, p.791-797, 2018.

http://dx.doi.org/10.1590/1983-

21252018v31n330rc

IBGE (Instituto Brasileiro de Geografia e Estatística). Sistema IBGE de Recuperação Automática - SIDRA. 2017. Disponível em: https://sidra.ibge.gov.br/tabela/1612.

Acesso em: 04 fev. 2019.

KIEHL, E.J. Manual de compostagem: maturação e qualidade do composto. Piracicaba, 6a ed., 2012, 171p.

LIMA, R. de L.S.; SEVERINO, L.S.; SILVA, M.I.L. JERÔNIMO, J.F.; do Vale, J.S.; BELTRÃO, N.E.M. Substratos para produção de mudas de mamoneira compostos por misturas de cinco fontes de matéria orgânica. Ciência e Agrotecnologia, Lavras, v.30, n.3, p.474-479, $2006 . \quad$ http://dx.doi.org/10.1590/S1413$\underline{70542006000300013}$

LOPES, M.A.C.; MUNIZ, R.V.S.; ALVES, S.S.V.; FERREIRA, A.C.; SÁ, V.S.; SILVA, L.A. Água salina e substratos no crescimento inicial do meloeiro. Irriga, Botucatu, v.22, n.3, p.469-484, 2017. https://doi.org/10.15809/irriga.2017v22n3p469$\underline{484}$

LUQUI, L.L., COSTA, E. ALVES, A.C. BINOTTI, F.F.S.; CARDOSO, E.D. Mudas de cultivares de pepineiro em diferentes substratos. Revista de Agricultura Neotropical, Cassilândia, v.2, n.1, p.1-9, 2015. https://doi.org/10.32404/rean.v2i1.252

MAGUIRE, J.D. Speed of germination aid in selection and evaluation for seedling emergence and vigor. Crop Science, Madison, v.2, n.2, p.17677, 1962.

http://dx.doi.org/10.2135/cropsci1962.0011183X $\underline{000200020033 x}$

MARTINS, C.C.; NAKAGAWA, J.; BOVI, M.L.A. Efeito da posição da semente no substrato e no crescimento inicial das plântulas de PalmitoVermelho (Euterpe espiritosantensis Fernandes Palmae). Revista Brasileira de Sementes, Brasília, v.21, n.1, p.164-173, 1999.

MEDEIROS, M.B.C.L.; JESUS, H.I.; SANTOS, N.F; MELO, M.R.S.; SOUZA, V.Q.; BORGES, L.S.B.; GUERREIRO, A.C.; FREITAS, L.S. Índice de qualidade de Dickson e característica morfológica de mudas de pepino, produzidas em diferentes substratos alternativos. Agroecossistemas, v.10, n.1, p.159-173, 2018.

http://dx.doi.org/10.18542/ragros.v10i1.5124

MINAMI, K.; PUCHALA B. Produção de mudas de hortaliças de alta qualidade. Horticultura Brasileira, Brasília, v.18. p162-63. 2000.

OLIVEIRA, I. V. M.; CAVALCANTE, I. H. L.; BECKMANN, M. Z.; MARTINS, A.B. G. Temperatura na Germinação de sementes de Sapota Preta. Revista de Biologia e Ciências da Terra, Campina Grande, v.5, n.2, p.1-7, 2005.

OLIVEIRA, P.M.; BLANK, A.F.; PEREIRA, A.J.; LIMA, L.A. Efeito da salinidade da água sobre a germinação de cultivares de melão. Revista Brasileira de Engenharia Agrícola e Ambiental, v.2, n.3, p.235-238, 1998.

PACHECO, A.; OLIVEIRA, G.Q.; LOPES, A.S.; BARBOSA, A.S. Manejos de irrigação e nitrogênio na produção de feijoeiro sob plantio direto. Pesquisa Agropecuária Tropical, Goiânia, v.42, n.3, p.323-330, 2012.

http://dx.doi.org/10.1590/S1983-

40632012000300004

PIRE, R.; VARGAS-SIMÓN, G. Recurrent inconsistencies in publications that involve Maguire's germination rate formula. Forest Systems, v.28, n.1, 2019.

http://dx.doi.org/10.5424/fs/2019281-14063 
PIRES, A.A.; MONNERAT, H.P.; MARCIANO, C.R.; PINHO, L.G.R.; ZAMPIROLLI, P.D.; ROSA, R.C.; MUNIZ, R.A. Efeito da adubação alternativa do maracujazeiro-amarelo nas características químicas e físicas do solo. Revista Brasileira de Ciência do Solo, Viçosa, v.32, n.5, p.1997-2005, $2008 . \quad$ http://dx.doi.org/10.1590/S0100$\underline{06832008000500021}$

RIBEIRO A.C; GUIMARÃES P.T.G; ALVAREZ V.H. 1999. (Eds.) Comissão de fertilidade do solo do Estado de Minas Gerais: Recomendações para o uso de corretivos e fertilizantes em Minas Gerais - 5a Aproximação. Viçosa, 360p.

SANTOS, R.S.S.; DIAS, N.S.; DUARTE, S.N.; LIMA, C.J.G.S.; FERNANDES, C.S.; MIRANDA, J.H.M. Cultivo da rúcula em substrato de fibra de coco sob solução nutritiva salina. Cultura Agronômica, Ilha Solteira, v.27, n.1, p.12-21, 2018.

SILVA JUNIOR, V.E.; VENDRUSCOLO, E.P.; SEMENSATO, L.R.; CAMPOS, L.F.C.; SELEGUINI, A. Esterco bovino como substrato alternativo na produção de mudas de melão. Revista Agropecuária Técnica, Areia, v.39, n.2, p.112119, 2018.

http://dx.doi.org/10.25066/agrotec.v39i2.37234

VENDRUSCOLO, E.P.; MARTINS, A.P.B.; SELEGUINI, A. Promoção no desenvolvimento de mudas olerícolas com uso de bioestimulante. Journal of Agronomic Sciences, Umuarama, v.5, n.2, p.73-82, 2016.

YASIR, M.; SULTANA, B.; NIGAM, P.S.; OWUSUAPENTEN, R. Antioxidant and genoprotective activity of selected cucurbitaceae seed extracts and LC-ESIMS/MS identification of phenolic components. Food Chemistry, v.199, p.307-313, 2016.

http://dx.doi.org/10.1016/i.foodchem.2015.11.1 $\underline{38}$

ZEIST, A.R.; RESENDE, J.T.V.; GIACOBBO, C.L.; FARIA, C.M.D.R.; DIAS, D M. Graft takes of tomato on other solanaceous plants. Revista Caatinga, v. 30, p. 513-520, 2017.

http://dx.doi.org/10.1590/1983-

$\underline{21252017 v 30 n 227 r}$

ZIETEMANN, C.; ROBERTO, S.R. Efeito de diferentes substratos e épocas de coleta no enraizamento de estacas herbáceas de goiabeira cvs. Paluma e Século XXI. Revista Brasileira de Fruticultura, Jaboticabal, v.29, n.1, p.31-36, 2007. http://dx.doi.org/10.1590/S0100$\underline{29452007000100009}$ 